Int. Agrophys., 2021, 35, 289-299

INTERNATIONAL

\title{
Response of some characteristics of selected beneficial soil microorganisms under different potassium fertilizer applications $* *$
}

\author{
Chandra S. Paul ${ }^{1}$, Saha Monidipta², Jiřina Száková1 ${ }^{1}$ *, Sahu N. Chandra ${ }^{2}$, and Pavel Tlustoš \\ ${ }^{1}$ Department of Agro-environmental Chemistry and Plant Nutrition, Czech University of Life Sciences, rague, Kamýcká 129 , \\ Prague Suchdol, 165 00, Czech Republic \\ ${ }^{2}$ Sasya Shyamala Krishi Vigyan Kendra, Ramakrishna Mission Vivekananda and Educational Research Institute, Arapanch, \\ Sonarpur, Kolkata-700150, West Bengal, India
}

Received August 23, 2021; accepted October 28, 2021

\begin{abstract}
Among the three important nutrients of (NPK) for plants, potassium plays a vital role in increasing disease resistance capacity and also in the activation of over 80 different enzymes responsible for plant metabolism. This article presents changes in the population of some soil beneficial microorganisms responsible for the nutrient cycling process in the soil and in their respiration activity as related to the application of different potassium $(\mathrm{K})$ fertilizers $\left(\mathrm{KCl}\right.$ and $\left.\mathrm{K}_{2} \mathrm{SO}_{4}\right)$ at different doses in a model incubation experiment. The application of $\mathrm{KCl}$ and $\mathrm{K}_{2} \mathrm{SO}_{4}$ fertilizers increases soil acidity at higher doses. The parameters describing the soil microbial community, i.e. microbial respiration and colony forming unit counts of free living $\mathrm{N}_{2}$-fixing bacteria, Rhizobium sp., Pseudomonas sp., potassium-solubilizing bacteria, and phosphate-solubilizing bacteria increased with the application of fertilizers at lower doses, but a minor decrease was observed for higher doses of fertilizers. The level of microbial activity showed a positive correlation with the application of different amounts of fertilizer but no effect was observed due to the use of different fertilizer types, thereby indicating that a substantial improvement in soil biological activities can be achieved regardless of the $\mathrm{K}$ fertilizer type at optimized doses.

Keywords: potassium fertilizer, soil health, soil biology, incubation experiment, sustainable fertilizer use
\end{abstract}

\section{INTRODUCTION}

India is the third largest user of nitrogen $(\mathrm{N})$, phosphorus $(\mathrm{P})$, and potassium $(\mathrm{K})$ fertilizers in the world, with an annual consumption of about 18 million tonnes of nitrogen,

*Corresponding author e-mail: szakova@af.czu.czn

**The study was supported by European Regional Development Fund - NutRisk Centre No. CZ.02.1.01/0.0/0.0/16_019/0000845 (2018-2023). phosphate and potassium fertilizers in total (Gurav et al., 2019). Potassium is one of the most applied plant nutrients, along with nitrogen and phosphorus. After nitrogen $(\mathrm{N})$ and phosphorus $(\mathrm{P})$, potassium $(\mathrm{K})$ is the most important plant nutrient that has a key role in the growth, metabolism and development of plants. In addition to increasing plant resistance to diseases, pests and abiotic stresses, $\mathrm{K}$ is required to activate over 80 different enzymes responsible for plant and animal processes, for instance, for energy metabolism, starch synthesis, nitrate reduction, photosynthesis and sugar degradation.

In the particular scenario of Indian agriculture, the use of nitrogen and phosphorus fertilizers is preferred by farmers, whereas potassium input is neglected and the potassium requirement of crops is ignored (Das et al., 2019). Pathak et al. (2010) documented that, in India, the major input of $\mathrm{K}$ came from irrigation water and rainfall whereas potassium fertilizer contributed only $26 \%$ of the total potassium (K) input in the soil. Moreover, long-term fertilizer experiments have shown that even the recommended rates of $\mathrm{K}$ application with nitrogen $(\mathrm{N})$ and phosphorous $(\mathrm{P})$ have failed to maintain the initial levels of available $\mathrm{K}$ in some soils (Das et al., 2019). As revealed by Gurav et al. (2019), the negative balance of $\mathrm{N}, \mathrm{P}$, and $\mathrm{K}$ in Indian agriculture is $19 \% \mathrm{~N}$, $12 \% \mathrm{P}$, and $69 \% \mathrm{~K}$. Potassium depletion occurs because crops remove an average of 1.5 times more potassium than

(C) 2021 Institute of Agrophysics, Polish Academy of Sciences 
nitrogen, and, simultaneously, the application of potassium through fertilizers in Indian agriculture is considerably lower than that of $\mathrm{N}$ or $\mathrm{P}$. As a result, even calcareous Vertisols containing a sufficient $\mathrm{K}$ supply for plant uptake (Gurav et al., 2018) can be transformed into K depleted soils with intensive crop production and without the application of $\mathrm{K}$ fertilizers (Ghiri and Abtahi, 2011). In a long-term (four decades) field experiment, Dhiman et al. (2019) documented substantial $\mathrm{K}$ depletion in plots with imbalanced (K-deficient) fertilizer application. Moreover, imbalanced fertilizer application caused adverse effects on soil biological properties such as microbial biomass carbon and nitrogen levels and resulted in a decrease in the yields of wheat grain and straw (Dhiman et al., 2019). Therefore, with the increasing cropping of $\mathrm{K}$ accumulating plants in India, more attention should be paid to maintaining a balanced $\mathrm{K}$ supply in soils, including an adequate $\mathrm{K}$ application to soils.

The most common potassium fertilizers are based on two main inorganic compounds i.e., potassium chloride (muriate of potash) and potassium sulphate (sulphate of potash). Potassium chloride $(\mathrm{KCl})$ is a common source of fertilizer and it is highly soluble; hence, excessive application may cause salt damage to plants (Rawat et al., 2016) through the buildup of salinity. Potassium sulphate $\left(\mathrm{K}_{2} \mathrm{SO}_{4}\right)$ is usually manufactured through the reaction of chloride with sulphuric acid, and it normally contains $43 \% \mathrm{~K}$ (Scherer, 2005). Potassium sulphate is also commercially available but is more expensive (Zörb et al., 2014). It is applied with particular frequency to horticultural crops in which chloride uptake is phytotoxic, such as tobacco plants (Rawat et al., 2016). It has been well established that the microbial soil community has the ability to influence soil fertility through soil processes such as decomposition, mineralization, and the storage/release of nutrients (Parmar and Sindhu, 2013).

It has been reported that some beneficial soil microorganisms, such as a wide range of heterotrophic bacteria, fungal strains and actinomycetes, significantly influence the fixation of nutrients, solubilize the insoluble form to a soluble form and activate the nutrient cycling processes. Some of these mechanisms include the production of inorganic and organic acids, polysaccharides, acidolysis, chelation, and exchange reactions. For the most part the heterotrophic $\mathrm{N}_{2}$ fixing bacteria, Rhizobium sp., Pseudomonas sp., phosphorous-solubilizing bacteria and potassium-mobilizing bacteria governs the nutrient cycling process in the soil through different mineralizing processes (nitrogen fixation, ammonification, nitrification, phosphate solubilization, potassium solubilization etc.) and are considered to be the primary indicator for understanding soil biological quality. The addition of a chemical fertilizer directly influences the soil microbial community, thus in order to develop a proper appreciation of ecosystem functioning, the biological condition of the soil ecosystem must be studied to evaluate the microbial status of the soil. Traditionally, the response to any changes at the microbial scale has been studied by evaluating the population, respiration rates and enzyme activities (Parkinson and Coleman, 1991). The actual interest in the effect of fertilizer on soil microbial population is driven by an awareness of the importance of soil microorganisms in controlling $\mathrm{C}, \mathrm{N}, \mathrm{P}$ and $\mathrm{S}$ flows in the soil through different processes (Sarathchandra et al., 1988). In order to assess the effects of applied chemical fertilizer, measuring changes in soil respiration of the active population of the soil, is an age old and reliable method. However, their population and activities are affected to a significant extent by the injudicious use of inorganic nutrient sources. Thus, applied fertilizers have a significant influence over the soil microbial community which includes their activities.

In general, chemical fertilizers play a significant role in increasing the productivity of soil; however, they may have a negative impact on soil fertility with respect to the soil microbial community and can cause environmental degradation as a result of excessive use (Das et al., 2019). Therefore, it is necessary to understand the response of beneficial soil microorganisms to the added fertilizers for improved microbial activity and also the specific properties of the different $\mathrm{K}$ compounds applied should be taken into account (Zörb et al., 2014). Moreover, the soil functioning and the sustainability of soil fertility are largely governed by the decomposition activity of microflora (Anderson, 2003). The structure, diversity, and activity of the soil microbial community have been used as indicators of overall soil health and productivity potential (Rasmussen et al., 1998; Böhme et al., 2005; Kaschuk et al., 2010; Mbuthia et al., 2015). Soil microorganisms play a significant role in the number of chemical transformations of soils and thus, influence the availability of macro- and micronutrients, potassium, and phosphorussolubilizing microorganisms play an important role (Meena et al., 2016). Efficient K- and P-solubilizing microorganisms should be applied for the solubilization of tightly bound forms of these nutrients to an available form of $\mathrm{K}$ and $\mathrm{P}$ in the soil (Verma et al., 2017; Yadav and Sidhu, 2016).

Thus, although the effect of potassium fertilizers on the activity of potassium-solubilizing bacteria has already been investigated, various aspects still remain which are less well understood. With the aforementioned observation in mind, a study was conducted to evaluate the influence of two different potassium fertilizers at different concentrations concerning the response of some soil beneficial microorganisms and their respiration activity. The main objective of the study was to assess the role of the potassium fertilizer type and rate of application in the stimulation of potassiumsolubilizing bacteria and/or other groups of the beneficial soil microorganisms in a short-term incubation experiment, as affected by various soil properties. 


\section{MATERIALS AND METHODS}

The laboratory incubation study was conducted in two soils of different texture, samples were collected from unfertilized plots of two different agro-climatic zones of West Bengal, India: Mandouri, Haringhata, Nadia (longitude $88.5674^{\circ} \mathrm{E}$ and latitude $22.9605^{\circ} \mathrm{N}$ ) for Soil-1 (New Alluvial zone, silty clay loam soil texture, Typic Haplaquepts) and Sudhangsupur, Gosaba, South 24 Parganas (Longitude $88.8079^{\circ} \mathrm{E}$ and Latitude $22.1652^{\circ} \mathrm{N}$ ) for Soil-2 (Coastal zone, silty clay soil texture, Typic Endoaquepts). The main characteristics of the experimental soils are summarized in Table 1. The soils had no cropping history for the last six months before collection for the study. For the laboratory incubation study, field moist surface soils $(0-15 \mathrm{~cm})$ from the abovementioned sites were collected in a labelled polythene bag and brought to the laboratory. The soils were air-dried. After the separation of stony materials and plant residues from the soils, the soil samples were sieved $(2 \mathrm{~mm})$ and homogenized. Depending on the dry weight of the soil, a particular amount $(2 \mathrm{~kg})$ was poured into clay pots for the incubation study (three replications). The incubation study was carried out under high-moisture conditions $(60 \%$ water-holding capacity) at room temperature $\left(25^{\circ} \mathrm{C}\right)$. Finely powdered oven-dried $\left(100^{\circ} \mathrm{C}\right.$ ) potassium chloride and potassium sulfate (Analytical grade) chemicals were applied at different concentrations (as calculated for the different doses) to the pre-weighed moist soil and mixed thoroughly to ensure the homogenized condition of the soil and fertilizer. The six different treatments based on fertilizer dose, along with the control, were defined as follows: $\mathrm{KCl}-1\left(40 \mathrm{~kg} \mathrm{ha}^{-1}\right), \mathrm{KCl}-2\left(110 \mathrm{~kg} \mathrm{ha}^{-1}\right), \mathrm{KCl}-3$ $\left(180 \mathrm{~kg} \mathrm{ha}^{-1}\right), \mathrm{K}_{2} \mathrm{SO}_{4}^{-4}\left(40 \mathrm{~kg} \mathrm{ha}^{-1}\right), \mathrm{K}_{2} \mathrm{SO}_{4}-5\left(110 \mathrm{~kg} \mathrm{ha}^{-1}\right)$, $\mathrm{K}_{2} \mathrm{SO}_{4}-6\left(180 \mathrm{~kg} \mathrm{ha}^{-1}\right)$ and control (no fertilizer). In order to keep the natural microbial community intact, no sterilization of the soil was performed prior to the treatment, but the clay pots were cleaned before incubation by spraying them with a $70 \%$ solution of ethanol. During the incubation periods, soil samples were collected on different incubation days $(0$, $3,7,15,30$, and 60) after application, they were collected separately in two polythene bags to determine the physicochemical parameters and for microbial analysis. Parameters, such as soil $\mathrm{pH}$, electrical conductivity $\left(\mathrm{EC}_{\mathrm{e}}\right)$, free-living $\mathrm{N}_{2}$-fixing bacteria, Rhizobium sp., Pseudomonas sp., potassium-solubilizing bacteria, phosphate-solubilizing bacteria and basal soil respiration were determined on specified days.

Table 1. Physicochemical properties of Mandouri, Haringhata (Soil-1), and Sudhangsupur, Gosaba (Soil-2) soils

\begin{tabular}{lcl}
\hline Soil property & Soil-1 & Soil-2 \\
\hline Water-holding capacity (\%) & 54 & 53 \\
$\mathrm{pH}$ & 6.1 & 6.3 \\
Electroconductivity $\left(\mathrm{EC}, \mathrm{dS} \mathrm{m}^{-1}\right)$ & 0.26 & 0.32 \\
Organic carbon $(\%)$ & 0.43 & 0.42 \\
Available phosphorus $\left(\mathrm{kg} \mathrm{ha}^{-1}\right)$ & 53.9 & 87.0 \\
Soil microbial respiration $\left(\mathrm{mg} \mathrm{CO}_{2} \mathrm{~g}^{-1}\right.$ of dry soil) & 1.3 & 2.7 \\
\hline
\end{tabular}

The $\mathrm{pH}$ of the soils was measured using a $\mathrm{pH}$ meter (Contech $\mathrm{CpH}-101$, India) in deionized water at a 1:2 soil:water ratio (Das et al., 2019). The EC of the soils was determined at a 1:2 soil:water ratio by using a digital EC meter (Systronics, TDS Meter 308, India).

The enumeration of the beneficial soil microbial population was performed using agar plates containing the appropriate media by following the serial dilution technique and spread plate method. Inoculated plates were incubated in an incubator at $28^{\circ} \mathrm{C}$ for $120 \mathrm{hs}$. The CFU counts were performed after 5 days of incubation. The specific media used were as follows: i) Jensen's Agar Medium (HiMedia ${ }^{\mathrm{TM}}$ ) for the population of nitrogen-fixing bacteria according to the method of Kayasth et al. (2014), ii) Yeast Mannitol Agar medium (HiMedia ${ }^{\mathrm{TM}}$ ) for the population of Rhizobium species, iii) Pikovskaya's Agar medium (Pikovskaya, 1948) for the population of phosphate-solubilizing soil microorganisms, iv) King's Medium B Base (HiMedia ${ }^{\mathrm{TM}}$ ) for the population of Pseudomonas sp., and v) Aleksandrow medium (HiMedia ${ }^{\mathrm{TM}}$ ) for the population of potassium-solubilizing bacteria. In order to determine the microbial activity of the treated soils under study, the basal respiration activity was estimated using $\mathrm{NaOH}$ entrapment of $\mathrm{CO}_{2}$ evolved due to microbial respiration according to the modified method of Alef (1991).

All statistical analyses were performed using Statistica 12.0 software (www.StatSoft.com). The effect of the different fertilizer doses was analysed using factorial analysis of variance (ANOVA, $p<0.05$ ), and Tukey's honestly significant difference (HSD) post-hoc test was used to determine the significant differences between the individual variables. The interactions of the treatment and other variables (e.g., soil, fertilizer type, fertilizer application rate, and incubation time) were analysed using the factorial ANOVA (Lindeman et al., 1980), in which the significance was assessed at $\mathrm{p}<0.05, \mathrm{p}<0.01$, and $\mathrm{p}<0.001$.

\section{RESULTS}

The changes in soil $\mathrm{pH}$ under different potassium fertilizer application doses are presented in Table 2. The study revealed that potassium fertilization through $\mathrm{KCl}$ and $\mathrm{K}_{2} \mathrm{SO}_{4}$ increased the soil acidity level as compared to the control for both soils under study, although the differences were not always verified as significant at $p<0.05$. The effect was only more prominent for higher doses of fertilizers after 15, 30 and 60 days of incubation for Soil-1, while for Soil-2 this occurred after 30 and 60 days of incubation. It was observed that the gradual increment in the application doses of both fertilizers increased soil acidity. The changes in the electrical conductivity of the saturated soil extract $\left(\mathrm{EC}_{\mathrm{e}}\right)$ values of the soils are presented in Table 3. As expected, an increase in $\mathrm{EC}_{\mathrm{e}}$ values was observed due to fertilizer application with a gradual increase with the increasing rate of fertilizer application. However, the changes were not always verified 
Tab le 2. Influence of using different potassium fertilizer application rates on the $\mathrm{pH}$ values of tested soils for 60 days of incubation

\begin{tabular}{|c|c|c|c|c|c|c|}
\hline \multirow{2}{*}{ Treatment } & \multicolumn{6}{|c|}{ Incubation days } \\
\hline & 0 & 3 & 7 & 15 & 30 & 60 \\
\hline \multicolumn{7}{|c|}{ Soil-1 } \\
\hline Control & $6.1 \pm 0.3^{\mathrm{ab}}$ & $6.1 \pm 0.2^{\mathrm{ab}}$ & $6.2 \pm 0.3^{\mathrm{a}}$ & $6.2 \pm 0.2^{\mathrm{b}}$ & $6.1 \pm 0.0^{\mathrm{c}}$ & $6.2 \pm 0.0^{\mathrm{c}}$ \\
\hline $\mathrm{KCl}-1$ & $5.9 \pm 0.1^{\mathrm{ab}}$ & $5.8 \pm 0.2^{\mathrm{ab}}$ & $5.7 \pm 0.4^{\mathrm{a}}$ & $5.6 \pm 0.2^{\mathrm{ab}}$ & $5.5 \pm 0.4^{\mathrm{ab}}$ & $5.1 \pm 0.2^{\mathrm{ab}}$ \\
\hline $\mathrm{KCl}-2$ & $5.7 \pm 0.4^{\mathrm{ab}}$ & $5.6 \pm 0.4^{\mathrm{ab}}$ & $5.5 \pm 0.3^{\mathrm{a}}$ & $5.4 \pm 0.3^{\mathrm{a}}$ & $5.2 \pm 0.1^{\mathrm{a}}$ & $4.9 \pm 0.2^{\mathrm{a}}$ \\
\hline $\mathrm{KCl}-3$ & $5.5 \pm 0.3^{\mathrm{a}}$ & $5.4 \pm 0.2^{\mathrm{a}}$ & $5.3 \pm 0.1^{\mathrm{a}}$ & $5.3 \pm 0.3^{\mathrm{a}}$ & $5.0 \pm 0.2^{\mathrm{a}}$ & $4.8 \pm 0.4^{\mathrm{a}}$ \\
\hline $\mathrm{K}_{2} \mathrm{SO}_{4}-1$ & $6.3 \pm 0.2^{\mathrm{b}}$ & $6.2 \pm 0.2^{\mathrm{b}}$ & $6.0 \pm 0.5^{\mathrm{a}}$ & $5.9 \pm 0.2^{\mathrm{a}}$ & $5.9 \pm 0.2^{\mathrm{bc}}$ & $5.8 \pm 0.3^{\mathrm{bc}}$ \\
\hline $\mathrm{K}_{2} \mathrm{SO}_{4}-2$ & $6.1 \pm 0.3^{\mathrm{ab}}$ & $5.9 \pm 0.3^{\mathrm{ab}}$ & $5.8 \pm 0.3^{\mathrm{a}}$ & $5.6 \pm 0.3^{\mathrm{ab}}$ & $5.5 \pm 0.4^{\mathrm{abc}}$ & $5.3 \pm 0.5^{\mathrm{ab}}$ \\
\hline $\mathrm{K}_{2} \mathrm{SO}_{4}-3$ & $6.0 \pm 0.4^{\mathrm{ab}}$ & $5.7 \pm 0.2^{\mathrm{ab}}$ & $5.6 \pm 0.3^{\mathrm{a}}$ & $5.4 \pm 0.4^{\mathrm{ab}}$ & $5.3 \pm 0.1^{\mathrm{a}}$ & $5.2 \pm 0.2^{\mathrm{ab}}$ \\
\hline \multicolumn{7}{|c|}{ Soil-2 } \\
\hline Control & $6.3 \pm 0.2^{\mathrm{b}}$ & $6.2 \pm 0.4^{\mathrm{b}}$ & $6.2 \pm 0.2^{\mathrm{b}}$ & $6.2 \pm 0.3^{\mathrm{a}}$ & $6.0 \pm 0.3^{\mathrm{a}}$ & $6.1 \pm 0.2^{c}$ \\
\hline $\mathrm{KCl}-1$ & $6.1 \pm 0.3^{\mathrm{ab}}$ & $6.0 \pm 0.3^{\mathrm{ab}}$ & $6.0 \pm 0.3^{\mathrm{ab}}$ & $5.9 \pm 0.2^{\mathrm{a}}$ & $5.9 \pm 0.2^{\mathrm{a}}$ & $5.7 \pm 0.3^{\mathrm{bc}}$ \\
\hline $\mathrm{KCl}-2$ & $6.0 \pm 0.3^{\mathrm{ab}}$ & $5.8 \pm 0.2^{\mathrm{ab}}$ & $5.7 \pm 0.3^{\mathrm{ab}}$ & $5.6 \pm 0.2^{\mathrm{a}}$ & $5.5 \pm 0.2^{\mathrm{ab}}$ & $5.3 \pm 0.2^{\mathrm{ab}}$ \\
\hline $\mathrm{KCl}-3$ & $5.8 \pm 0.3^{\mathrm{ab}}$ & $5.6 \pm 0.3^{\mathrm{ab}}$ & $5.5 \pm 0.5^{\mathrm{ab}}$ & $5.5 \pm 0.3^{\mathrm{a}}$ & $5.4 \pm 0.2^{\mathrm{abc}}$ & $5.2 \pm 0.2^{\mathrm{ab}}$ \\
\hline $\mathrm{K}_{2} \mathrm{SO}_{4}-1$ & $6.0 \pm 0.3^{\mathrm{ab}}$ & $5.9 \pm 0.2^{\mathrm{ab}}$ & $5.8 \pm 0.3^{\mathrm{ab}}$ & $5.8 \pm 0.4^{\mathrm{a}}$ & $5.6 \pm 0.1^{\mathrm{ab}}$ & $5.2 \pm 0.3^{\mathrm{ab}}$ \\
\hline $\mathrm{K}_{2} \mathrm{SO}_{4}-2$ & $5.8 \pm 0.4^{\mathrm{ab}}$ & $5.7 \pm 0.3^{\mathrm{ab}}$ & $5.6 \pm 0.2^{\mathrm{ab}}$ & $5.5 \pm 0.2^{\mathrm{a}}$ & $5.3 \pm 0.3^{b c}$ & $5.0 \pm 0.2^{\mathrm{a}}$ \\
\hline $\mathrm{K}_{2} \mathrm{SO}_{4}-3$ & $5.4 \pm 0.4^{\mathrm{a}}$ & $5.4 \pm 0.2^{\mathrm{a}}$ & $5.2 \pm 0.2^{\mathrm{a}}$ & $5.4 \pm 0.3^{\mathrm{a}}$ & $4.9 \pm 0.2^{c}$ & $4.9 \pm 0.2^{\mathrm{a}}$ \\
\hline
\end{tabular}

The averages are indicated by the use of the same letter and did not significantly differ at $\mathrm{p}<0.05$ within individual columns and soils; the data are presented as mean \pm standard deviation, $n=3$

Table 3. Influence of using different potassium fertilizer rates of application on the EC $\left(\mathrm{ds} \mathrm{m}^{-1}\right)$ values of the tested soils for 60 days of incubation

\begin{tabular}{|c|c|c|c|c|c|c|}
\hline \multirow{2}{*}{ Treatment } & \multicolumn{6}{|c|}{ Incubation days } \\
\hline & 0 & 3 & 7 & 15 & 30 & 60 \\
\hline \multicolumn{7}{|c|}{ Soil-1 } \\
\hline Control & $0.26 \pm 0.02^{\mathrm{b}}$ & $0.28 \pm 0.08^{\mathrm{c}}$ & $0.24 \pm 0.05^{\mathrm{d}}$ & $0.27 \pm 0.08^{\mathrm{e}}$ & $0.22 \pm 0.02^{\mathrm{d}}$ & $0.37 \pm 0.05^{\mathrm{c}}$ \\
\hline $\mathrm{KCl}-1$ & $0.38 \pm 0.04^{\mathrm{a}}$ & $0.51 \pm 0.10^{\mathrm{ab}}$ & $0.54 \pm 0.06^{\mathrm{a}}$ & $0.51 \pm 0.05^{\mathrm{a}}$ & $0.53 \pm 0.07^{\mathrm{b}}$ & $0.57 \pm 0.06^{\mathrm{a}}$ \\
\hline $\mathrm{KCl}-2$ & $0.46 \pm 0.03^{\mathrm{a}}$ & $0.61 \pm 0.06^{\mathrm{bd}}$ & $0.78 \pm 0.05^{\mathrm{bc}}$ & $0.68 \pm 0.05^{\mathrm{bcd}}$ & $0.60 \pm 0.07^{\mathrm{ab}}$ & $0.58 \pm 0.06^{\mathrm{a}}$ \\
\hline $\mathrm{KCl}-3$ & $0.59 \pm 0.02^{\mathrm{c}}$ & $0.77 \pm 0.08^{\mathrm{d}}$ & $0.82 \pm 0.06^{\mathrm{c}}$ & $0.81 \pm 0.05^{\mathrm{d}}$ & $0.83 \pm 0.06^{\mathrm{c}}$ & $0.80 \pm 0.06^{\mathrm{b}}$ \\
\hline $\mathrm{K}_{2} \mathrm{SO}_{4}-1$ & $0.27 \pm 0.03^{\mathrm{b}}$ & $0.40 \pm 0.07^{\mathrm{ac}}$ & $0.44 \pm 0.07^{\mathrm{a}}$ & $0.54 \pm 0.03^{\mathrm{ab}}$ & $0.57 \pm 0.05^{\mathrm{ab}}$ & $0.63 \pm 0.06^{\mathrm{ab}}$ \\
\hline $\mathrm{K}_{2} \mathrm{SO}_{4}-2$ & $0.38 \pm 0.03^{\mathrm{a}}$ & $0.52 \pm 0.06^{\mathrm{ab}}$ & $0.58 \pm 0.07^{\mathrm{ab}}$ & $0.61 \pm 0.04^{\mathrm{abc}}$ & $0.69 \pm 0.05^{\mathrm{ac}}$ & $0.72 \pm 0.07^{\mathrm{ab}}$ \\
\hline $\mathrm{K}_{2} \mathrm{SO}_{4}-3$ & $0.43 \pm 0.04^{\mathrm{a}}$ & $0.50 \pm 0.05^{\mathrm{ab}}$ & $0.55 \pm 0.12^{\mathrm{a}}$ & $0.71 \pm 0.06^{\mathrm{cd}}$ & $0.68 \pm 0.04^{\mathrm{ac}}$ & $0.72 \pm 0.07^{\mathrm{ab}}$ \\
\hline \multicolumn{7}{|c|}{ Soil-2 } \\
\hline Control & $0.32 \pm 0.03^{\mathrm{c}}$ & $0.36 \pm 0.03^{c}$ & $0.34 \pm 0.03^{\mathrm{c}}$ & $0.29 \pm 0.02^{\mathrm{d}}$ & $0.39 \pm 0.02^{\mathrm{c}}$ & $0.31 \pm 0.02^{\mathrm{c}}$ \\
\hline $\mathrm{KCl}-1$ & $0.46 \pm 0.04^{\mathrm{b}}$ & $0.55 \pm 0.02^{\mathrm{a}}$ & $0.60 \pm 0.02^{\mathrm{a}}$ & $0.61 \pm 0.03^{\mathrm{c}}$ & $0.64 \pm 0.01^{\mathrm{b}}$ & $0.67 \pm 0.01^{\mathrm{b}}$ \\
\hline $\mathrm{KCl}-2$ & $0.71 \pm 0.03^{\mathrm{a}}$ & $0.67 \pm 0.03^{\mathrm{b}}$ & $0.78 \pm 0.01^{\mathrm{b}}$ & $0.59 \pm 0.02^{\mathrm{bc}}$ & $0.67 \pm 0.01^{\mathrm{ab}}$ & $0.66 \pm 0.03^{b}$ \\
\hline $\mathrm{KCl}-3$ & $0.72 \pm 0.03^{\mathrm{a}}$ & $0.88 \pm 0.05^{\mathrm{e}}$ & $0.87 \pm 0.02^{\mathrm{e}}$ & $0.79 \pm 0.01^{\mathrm{a}}$ & $0.81 \pm 0.03^{\mathrm{d}}$ & $0.79 \pm 0.01^{\mathrm{a}}$ \\
\hline $\mathrm{K}_{2} \mathrm{SO}_{4}-1$ & $0.51 \pm 0.02^{\mathrm{b}}$ & $0.54 \pm 0.03^{\mathrm{a}}$ & $0.56 \pm 0.03^{\mathrm{a}}$ & $0.54 \pm 0.03^{\mathrm{b}}$ & $0.70 \pm 0.02^{\mathrm{a}}$ & $0.79 \pm 0.02^{\mathrm{a}}$ \\
\hline $\mathrm{K}_{2} \mathrm{SO}_{4}-2$ & $0.73 \pm 0.03^{\mathrm{a}}$ & $0.61 \pm 0.02^{\mathrm{ab}}$ & $0.68 \pm 0.04^{\mathrm{d}}$ & $0.79 \pm 0.02^{\mathrm{a}}$ & $0.69 \pm 0.03^{\mathrm{ab}}$ & $0.77 \pm 0.03^{\mathrm{a}}$ \\
\hline $\mathrm{K}_{2} \mathrm{SO}_{4}-3$ & $0.71 \pm 0.02^{\mathrm{a}}$ & $0.76 \pm 0.03^{\mathrm{d}}$ & $0.80 \pm 0.02^{\mathrm{b}}$ & $0.82 \pm 0.04^{\mathrm{a}}$ & $0.70 \pm 0.02^{\mathrm{a}}$ & $0.80 \pm 0.03^{\mathrm{a}}$ \\
\hline
\end{tabular}

Explanations as in Table 2.

as significant at $\mathrm{p}<0.05$. The changes in soil microbial respiration are summarized in Table 4 . The results indicated that the application of both $\mathrm{KCl}$ and $\mathrm{K}_{2} \mathrm{SO}_{4}$ significantly increased the level of basal soil respiration in comparison to the level in the untreated soil, but only marginal effects of the fertilizer type and rate were recorded, in particular with reference to the incubation days studied at the beginning of the incubation period, where no significant $(\mathrm{p}<0.05)$ differences were recorded for the incubation days 0 and 3 .

The changes in the populations of free-living $\mathrm{N}_{2}$-fixing bacteria, Rhizobium sp., Pseudomonas sp., potassiumsolubilizing bacteria, phosphate-solubilizing bacteria in the two soils treated with a stepwise increasing rate of $\mathrm{K}$ fertilizer application, expressed in terms of CFUs, which are presented in Tables 5-9. In Soil-1, a higher concentration of $\mathrm{K}$ fertilizer application tended to decrease (without a clear statistical verification at $\mathrm{p}<0.05$ ) the nitrogen-fixing populations in comparison with the lower dose application (Table 5). In contrast, the effect of $\mathrm{KCl}$ application was not so prominent in Soil-2. At day 3, an increase in the nitrogen-fixing population was observed at higher doses. This increase was recorded again for days 30 and 60 in Soil-1, whereas no significant changes in population occurred at these days in the Soil-2. 
Table 4. Influence of using different potassium fertilizer application rates on the basal soil respiration $\left(\mathrm{mg} \mathrm{CO}_{2}\right.$ released $\mathrm{g}^{-1}$ of ovendried soil) values of the tested soils for 60 days of incubation

\begin{tabular}{|c|c|c|c|c|c|c|}
\hline \multirow{2}{*}{ Treatment } & \multicolumn{6}{|c|}{ Incubation days } \\
\hline & 0 & 3 & 7 & 15 & 30 & 60 \\
\hline \multicolumn{7}{|c|}{ Soil-1 } \\
\hline Control & $1.3 \pm 0.09^{\mathrm{a}}$ & $1.7 \pm 0.28^{\mathrm{a}}$ & $1.6 \pm 0.12^{\mathrm{b}}$ & $2.1 \pm 0.23^{\mathrm{b}}$ & $2.1 \pm 0.08^{c}$ & $1.5 \pm 0.30^{\mathrm{b}}$ \\
\hline $\mathrm{KCl}-1$ & $1.6 \pm 0.33^{\mathrm{a}}$ & $1.9 \pm 0.68^{\mathrm{a}}$ & $2.9 \pm 0.42^{\mathrm{a}}$ & $3.8 \pm 0.55^{\mathrm{a}}$ & $5.0 \pm 0.02^{\mathrm{a}}$ & $4.1 \pm 0.81^{\mathrm{a}}$ \\
\hline $\mathrm{KCl}-2$ & $1.3 \pm 0.06^{\mathrm{a}}$ & $1.9 \pm 0.52^{\mathrm{a}}$ & $2.9 \pm 0.28^{\mathrm{a}}$ & $4.1 \pm 0.42^{\mathrm{a}}$ & $4.2 \pm 0.13^{\mathrm{b}}$ & $4.2 \pm 0.21^{\mathrm{a}}$ \\
\hline $\mathrm{KCl}-3$ & $1.3 \pm 0.13^{\mathrm{a}}$ & $1.9 \pm 0.42^{\mathrm{a}}$ & $3.1 \pm 0.41^{\mathrm{a}}$ & $4.6 \pm 0.32^{\mathrm{a}}$ & $4.6 \pm 0.32^{\mathrm{ab}}$ & $4.3 \pm 0.63^{\mathrm{a}}$ \\
\hline $\mathrm{K}_{2} \mathrm{SO}_{4}-1$ & $1.4 \pm 0.14^{\mathrm{a}}$ & $2.1 \pm 0.53^{\mathrm{a}}$ & $3.1 \pm 0.56^{\mathrm{a}}$ & $4.1 \pm 0.15^{\mathrm{a}}$ & $4.6 \pm 0.31^{\mathrm{ab}}$ & $4.1 \pm 0.84^{\mathrm{a}}$ \\
\hline $\mathrm{K}_{2} \mathrm{SO}_{4}-2$ & $1.3 \pm 0.06^{\mathrm{a}}$ & $2.3 \pm 0.58^{\mathrm{a}}$ & $2.9 \pm 0.35^{\mathrm{a}}$ & $4.2 \pm 0.15^{\mathrm{a}}$ & $5.3 \pm 0.48^{\mathrm{a}}$ & $4.9 \pm 0.46^{\mathrm{a}}$ \\
\hline $\mathrm{K}_{2} \mathrm{SO}_{4}-3$ & $1.4 \pm 0.10^{\mathrm{a}}$ & $2.3 \pm 0.93^{\mathrm{a}}$ & $3.3 \pm 0.16^{\mathrm{a}}$ & $4.5 \pm 0.38^{\mathrm{a}}$ & $5.4 \pm 0.28^{\mathrm{a}}$ & $4.6 \pm 0.67^{\mathrm{a}}$ \\
\hline \multicolumn{7}{|c|}{ Soil-2 } \\
\hline Control & $2.7 \pm 0.36^{\mathrm{a}}$ & $2.7 \pm 0.24^{\mathrm{a}}$ & $2.4 \pm 0.25^{\mathrm{b}}$ & $2.2 \pm 0.28^{\mathrm{c}}$ & $2.3 \pm 0.17^{\mathrm{d}}$ & $2.8 \pm 0.27^{\mathrm{b}}$ \\
\hline $\mathrm{KCl}-1$ & $2.4 \pm 0.08^{\mathrm{a}}$ & $2.7 \pm 0.16^{\mathrm{a}}$ & $3.3 \pm 0.27^{\mathrm{ab}}$ & $5.1 \pm 0.09^{\mathrm{b}}$ & $3.6 \pm 0.35^{\mathrm{a}}$ & $3.8 \pm 0.50^{\mathrm{ab}}$ \\
\hline $\mathrm{KCl}-2$ & $2.8 \pm 0.07^{\mathrm{a}}$ & $2.8 \pm 0.28^{\mathrm{a}}$ & $3.2 \pm 0.69^{\mathrm{ab}}$ & $4.8 \pm 0.18^{\mathrm{ab}}$ & $3.7 \pm 0.53^{\mathrm{a}}$ & $4.1 \pm 0.54^{\mathrm{ab}}$ \\
\hline $\mathrm{KCl}-3$ & $2.7 \pm 0.15^{\mathrm{a}}$ & $3.2 \pm 0.06^{\mathrm{a}}$ & $3.7 \pm 0.43^{\mathrm{a}}$ & $4.4 \pm 0.09^{\mathrm{ab}}$ & $4.0 \pm 0.13^{\mathrm{ac}}$ & $4.0 \pm 1.19^{\mathrm{ab}}$ \\
\hline $\mathrm{K}_{2} \mathrm{SO}_{4}-1$ & $2.4 \pm 0.33^{\mathrm{a}}$ & $2.8 \pm 0.55^{\mathrm{a}}$ & $3.1 \pm 0.20^{\mathrm{ab}}$ & $4.1 \pm 0.70^{\mathrm{a}}$ & $4.8 \pm 0.36^{\mathrm{bc}}$ & $4.6 \pm 0.30^{\mathrm{a}}$ \\
\hline $\mathrm{K}_{2} \mathrm{SO}_{4}-2$ & $2.6 \pm 0.10^{\mathrm{a}}$ & $3.5 \pm 0.30^{\mathrm{a}}$ & $2.8 \pm 0.19^{\mathrm{ab}}$ & $4.1 \pm 0.44^{\mathrm{a}}$ & $5.0 \pm 0.41^{\mathrm{b}}$ & $4.7 \pm 0.16^{\mathrm{a}}$ \\
\hline $\mathrm{K}_{2} \mathrm{SO}_{4}-3$ & $2.8 \pm 0.17^{\mathrm{a}}$ & $3.5 \pm 0.20^{\mathrm{a}}$ & $3.7 \pm 0.27^{\mathrm{a}}$ & $4.5 \pm 0.31^{\mathrm{ab}}$ & $5.6 \pm 0.18^{\mathrm{b}}$ & $5.2 \pm 0.20^{\mathrm{a}}$ \\
\hline
\end{tabular}

Explanations as in Table 2.

Tab le 5. Influence of using different potassium fertilizer application rates on the number of nitrogen-fixing bacteria (x $10^{5} \mathrm{CFUs}^{-1} \mathrm{dry} \mathrm{soil)}$ in the tested soils for 60 days of incubation

\begin{tabular}{|c|c|c|c|c|c|c|}
\hline \multirow{2}{*}{ Treatment } & \multicolumn{6}{|c|}{ Incubation days } \\
\hline & 0 & 3 & 7 & 15 & 30 & 60 \\
\hline \multicolumn{7}{|c|}{ Soil-1 } \\
\hline Control & $32.7 \pm 8.6^{\mathrm{a}}$ & $34.3 \pm 1.5^{\mathrm{c}}$ & $39.0 \pm 4.4^{\mathrm{a}}$ & $34.3 \pm 3.5^{\mathrm{a}}$ & $30.0 \pm 5.3^{\mathrm{b}}$ & $26.3 \pm 2.5^{\mathrm{b}}$ \\
\hline $\mathrm{KCl}-1$ & $31.0 \pm 2.0^{\mathrm{a}}$ & $54.3 \pm 5.0^{\mathrm{d}}$ & $51.7 \pm 3.1^{\mathrm{c}}$ & $46.7 \pm 5.0^{\mathrm{a}}$ & $46.0 \pm 3.6^{\mathrm{a}}$ & $56.0 \pm 3.6^{\mathrm{a}}$ \\
\hline $\mathrm{KCl}-2$ & $35.3 \pm 1.5^{\mathrm{a}}$ & $41.3 \pm 1.5^{\mathrm{abc}}$ & $48.3 \pm 2.3^{\mathrm{bc}}$ & $46.7 \pm 6.5^{\mathrm{a}}$ & $50.7 \pm 4.2^{\mathrm{a}}$ & $44.7 \pm 5.9^{\mathrm{a}}$ \\
\hline $\mathrm{KCl}-3$ & $33.3 \pm 4.0^{\mathrm{a}}$ & $46.3 \pm 2.5^{\text {abd }}$ & $41.7 \pm 4.0^{\mathrm{ab}}$ & $42.3 \pm 3.5^{\mathrm{a}}$ & $47.7 \pm 7.4^{\mathrm{a}}$ & $43.3 \pm 6.4^{\mathrm{a}}$ \\
\hline $\mathrm{K}_{2} \mathrm{SO}_{4}-1$ & $31.3 \pm 3.2^{\mathrm{a}}$ & $39.0 \pm 3.6^{\mathrm{ac}}$ & $41.3 \pm 2.5^{\mathrm{ab}}$ & $39.7 \pm 4.0^{\mathrm{a}}$ & $47.0 \pm 2.6^{\mathrm{a}}$ & $51.3 \pm 5.7^{\mathrm{a}}$ \\
\hline $\mathrm{K}_{2} \mathrm{SO}_{4}-2$ & $32.7 \pm 2.1^{\mathrm{a}}$ & $45.3 \pm 2.5^{\mathrm{ab}}$ & $43.7 \pm 3.1^{\mathrm{abc}}$ & $41.7 \pm 5.5^{\mathrm{a}}$ & $43.7 \pm 2.1^{\mathrm{a}}$ & $42.7 \pm 5.0^{\mathrm{a}}$ \\
\hline $\mathrm{K}_{2} \mathrm{SO}_{4}-3$ & $33.7 \pm 3.5^{\mathrm{a}}$ & $48.7 \pm 3.1^{\mathrm{bd}}$ & $35.7 \pm 3.5^{\mathrm{a}}$ & $39.7 \pm 3.1^{\mathrm{a}}$ & $49.3 \pm 3.1^{\mathrm{a}}$ & $50.0 \pm 5.2^{\mathrm{a}}$ \\
\hline \multicolumn{7}{|c|}{ Soil-2 } \\
\hline Control & $39.7 \pm 3.1^{\mathrm{ab}}$ & $40.0 \pm 6.6^{b}$ & $34.3 \pm 0.6^{\mathrm{a}}$ & $35.0 \pm 1.0^{\mathrm{a}}$ & $37.3 \pm 1.5^{\mathrm{a}}$ & $36.3 \pm 2.1^{\mathrm{a}}$ \\
\hline $\mathrm{KCl}-1$ & $52.7 \pm 4.0^{\mathrm{d}}$ & $39.3 \pm 2.5^{\mathrm{a}}$ & $55.7 \pm 2.5^{\mathrm{a}}$ & $57.7 \pm 3.5^{\mathrm{a}}$ & $47.7 \pm 4.7^{\mathrm{a}}$ & $66.7 \pm 4.0^{\mathrm{a}}$ \\
\hline $\mathrm{KCl}-2$ & $56.3 \pm 4.5^{b c}$ & $49.0 \pm 2.0^{\mathrm{a}}$ & $53.3 \pm 2.5^{\mathrm{a}}$ & $52.7 \pm 2.5^{\mathrm{a}}$ & $50.7 \pm 4.7^{\mathrm{a}}$ & $34.3 \pm 2.9^{\mathrm{a}}$ \\
\hline $\mathrm{KCl}-3$ & $58.3 \pm 2.5^{\mathrm{a}}$ & $46.7 \pm 2.1^{\mathrm{ab}}$ & $56.3 \pm 3.5^{\mathrm{a}}$ & $54.0 \pm 5.0^{\mathrm{a}}$ & $50.0 \pm 8.0^{\mathrm{a}}$ & $42.3 \pm 4.5^{\mathrm{a}}$ \\
\hline $\mathrm{K}_{2} \mathrm{SO}_{4}-1$ & $55.0 \pm 3.0^{\mathrm{cd}}$ & $52.3 \pm 3.5^{\mathrm{a}}$ & $58.7 \pm 5.5^{\mathrm{a}}$ & $62.0 \pm 3.0^{\mathrm{a}}$ & $61.0 \pm 3.0^{\mathrm{a}}$ & $52.3 \pm 4.9^{\mathrm{a}}$ \\
\hline $\mathrm{K}_{2} \mathrm{SO}_{4}-2$ & $56.3 \pm 2.5^{\mathrm{ab}}$ & $53.0 \pm 2.6^{\mathrm{ab}}$ & $45.7 \pm 3.5^{\mathrm{a}}$ & $63.0 \pm 4.6^{\mathrm{a}}$ & $60.3 \pm 6.8^{\mathrm{a}}$ & $63.0 \pm 4.0^{\mathrm{a}}$ \\
\hline $\mathrm{K}_{2} \mathrm{SO}_{4}-3$ & $47.7 \pm 4.5^{\mathrm{cd}}$ & $51.0 \pm 2.0^{\mathrm{ab}}$ & $49.3 \pm 3.5^{\mathrm{a}}$ & $63.7 \pm 7.0^{\mathrm{a}}$ & $58.0 \pm 9.5^{\mathrm{a}}$ & $61.3 \pm 5.5^{\mathrm{a}}$ \\
\hline
\end{tabular}

Explanations as in Table 2.

For the Rhizobium sp. population in Soil-1 (Table 6), the $\mathrm{CFU}$ values showed similar trends to those of the nitrogenfixing bacteria for $\mathrm{KCl}$-treated variants at day 3 , whereas no significant changes were found for the subsequent days in the study. Moreover, no significant changes in population were observed with increases in the fertilizer application rate. The results indicated the stimulating effect of $\mathrm{KCl}$ application on the population that was for the most part unaffected by fertilization rates. A different pattern was observed in Soil-2, in which the significant $(p<0.05)$ increase in CFUs in the treated soils as compared to the control was recorded for days 15 and 30. Again, an increase in the Rhizobium sp. population was recorded with lower doses of fertilizer application relative to the results produced by the control and no further increase was observed with the increasing rate of fertilizer application. Changes in CFU counts of Pseudomonas sp. in soils with different doses of fertilizer and different incubation periods are presented in Table 7. The results indicate that application of both $\mathrm{KCl}$ and $\mathrm{K}_{2} \mathrm{SO}_{4}$ favoured the growth of bacteria and significantly $(p<0.05)$ increased their population relative to those in the untreated soil for most of the sampling days. Although not always verified as significant at $p<0.05$, the results tended to increase with the increasing rate of fertilizer application. 
Table 6. Influence of using different potassium fertilizer application rates on the number of Rhizobium sp. (x $10^{5} \mathrm{CFUs}^{-1} \mathrm{dry} \mathrm{soil)}$ in the tested soils for 60 days of incubation

\begin{tabular}{|c|c|c|c|c|c|c|}
\hline \multirow{2}{*}{ Treatment } & \multicolumn{6}{|c|}{ Incubation days } \\
\hline & 0 & 3 & 7 & 15 & 30 & 60 \\
\hline \multicolumn{7}{|c|}{ Soil-1 } \\
\hline Control & $36.3 \pm 0.6^{\mathrm{ab}}$ & $35.0 \pm 2.6^{\mathrm{b}}$ & $39.7 \pm 5.0^{\mathrm{a}}$ & $36.7 \pm 1.2^{\mathrm{a}}$ & $35.7 \pm 5.9^{\mathrm{a}}$ & $39.7 \pm 6.7^{\mathrm{a}}$ \\
\hline $\mathrm{KCl}-1$ & $44.0 \pm 2.0^{\mathrm{d}}$ & $44.0 \pm 2.0^{\mathrm{a}}$ & $46.7 \pm 4.7^{\mathrm{a}}$ & $51.0 \pm 12.8^{\mathrm{a}}$ & $50.0 \pm 6.6^{\mathrm{a}}$ & $39.7 \pm 3.1^{\mathrm{a}}$ \\
\hline $\mathrm{KCl}-2$ & $39.7 \pm 1.2^{\mathrm{bc}}$ & $42.7 \pm 1.5^{\mathrm{a}}$ & $44.7 \pm 4.2^{\mathrm{a}}$ & $55.0 \pm 9.2^{\mathrm{a}}$ & $53.7 \pm 8.0^{\mathrm{a}}$ & $37.3 \pm 3.2^{\mathrm{a}}$ \\
\hline $\mathrm{KCl}-3$ & $35.3 \pm 1.2^{\mathrm{a}}$ & $39.3 \pm 2.5^{\mathrm{ab}}$ & $45.0 \pm 4.0^{\mathrm{a}}$ & $51.0 \pm 14.2^{\mathrm{a}}$ & $52.0 \pm 4.4^{\mathrm{a}}$ & $36.7 \pm 2.5^{\mathrm{a}}$ \\
\hline $\mathrm{K}_{2} \mathrm{SO}_{4}-1$ & $42.3 \pm 1.5^{\mathrm{cd}}$ & $44.3 \pm 1.5^{\mathrm{a}}$ & $43.0 \pm 3.0^{\mathrm{a}}$ & $51.3 \pm 13.9^{\mathrm{a}}$ & $53.0 \pm 9.8^{\mathrm{a}}$ & $36.3 \pm 4.2^{\mathrm{a}}$ \\
\hline $\mathrm{K}_{2} \mathrm{SO}_{4}-2$ & $37.3 \pm 1.5^{\mathrm{ab}}$ & $38.7 \pm 3.5^{\mathrm{ab}}$ & $43.3 \pm 4.0^{\mathrm{a}}$ & $54.7 \pm 18.0^{\mathrm{a}}$ & $51.0 \pm 6.2^{\mathrm{a}}$ & $45.3 \pm 4.5^{\mathrm{a}}$ \\
\hline $\mathrm{K}_{2} \mathrm{SO}_{4}-3$ & $42.0 \pm 1.0^{\mathrm{cd}}$ & $39.3 \pm 2.1^{\mathrm{ab}}$ & $44.0 \pm 2.6^{\mathrm{a}}$ & $50.7 \pm 15.6^{\mathrm{a}}$ & $52.3 \pm 7.1^{\mathrm{a}}$ & $45.3 \pm 7.2^{\mathrm{a}}$ \\
\hline \multicolumn{7}{|c|}{ Soil-2 } \\
\hline Control & $34.7 \pm 2.1^{\mathrm{a}}$ & $36.3 \pm 2.1^{\mathrm{a}}$ & $36.3 \pm 2.5^{\mathrm{a}}$ & $34.3 \pm 1.5^{\mathrm{c}}$ & $35.3 \pm 0.6^{\mathrm{b}}$ & $38.0 \pm 1.0^{\mathrm{a}}$ \\
\hline $\mathrm{KCl}-1$ & $33.7 \pm 2.5^{\mathrm{a}}$ & $36.7 \pm 5.0^{\mathrm{a}}$ & $40.7 \pm 5.7^{\mathrm{a}}$ & $39.7 \pm 4.9^{\mathrm{ac}}$ & $62.3 \pm 1.2^{\mathrm{a}}$ & $53.3 \pm 9.9^{\mathrm{a}}$ \\
\hline $\mathrm{KCl}-2$ & $36.3 \pm 2.5^{\mathrm{a}}$ & $35.0 \pm 3.6^{\mathrm{a}}$ & $39.7 \pm 8.1^{\mathrm{a}}$ & $44.3 \pm 2.1^{\mathrm{ab}}$ & $59.3 \pm 5.1^{\mathrm{a}}$ & $47.7 \pm 9.6^{\mathrm{a}}$ \\
\hline $\mathrm{KCl}-3$ & $35.0 \pm 4.4^{\mathrm{a}}$ & $34.0 \pm 7.5^{\mathrm{a}}$ & $45.0 \pm 6.6^{\mathrm{a}}$ & $40.3 \pm 3.2^{\mathrm{abc}}$ & $57.7 \pm 5.7^{\mathrm{a}}$ & $38.0 \pm 3.5^{\mathrm{a}}$ \\
\hline $\mathrm{K}_{2} \mathrm{SO}_{4}-1$ & $33.7 \pm 2.5^{\mathrm{a}}$ & $39.0 \pm 7.5^{\mathrm{a}}$ & $38.0 \pm 6.6^{\mathrm{a}}$ & $47.7 \pm 1.5^{\mathrm{ab}}$ & $57.3 \pm 6.5^{\mathrm{a}}$ & $52.7 \pm 8.7^{\mathrm{a}}$ \\
\hline $\mathrm{K}_{2} \mathrm{SO}_{4}-2$ & $35.0 \pm 6.0^{\mathrm{a}}$ & $37.3 \pm 7.2^{\mathrm{a}}$ & $37.0 \pm 4.6^{\mathrm{a}}$ & $48.7 \pm 4.2^{\mathrm{b}}$ & $53.0 \pm 5.6^{\mathrm{a}}$ & $40.0 \pm 1.0^{\mathrm{a}}$ \\
\hline$\underline{\mathrm{K}_{2} \mathrm{SO}_{4}-3}$ & $37.3 \pm 3.1^{\mathrm{a}}$ & $36.3 \pm 6.4^{\mathrm{a}}$ & $34.7 \pm 5.1^{\mathrm{a}}$ & $44.3 \pm 3.1^{\mathrm{ab}}$ & $56.3 \pm 6.0^{\mathrm{a}}$ & $41.7 \pm 4.5^{\mathrm{a}}$ \\
\hline
\end{tabular}

Explanations as in Table 2.

Table 7. Influence of using different potassium fertilizers application rates on the number of Pseudomonas sp. (x $10^{5}$ CFUs $\mathrm{g}^{-1}$ dry soil) in the tested soils for 60 days of incubation

\begin{tabular}{|c|c|c|c|c|c|c|}
\hline \multirow{2}{*}{ Treatment } & \multicolumn{6}{|c|}{ Incubation days } \\
\hline & 0 & 3 & 7 & 15 & 30 & 60 \\
\hline \multicolumn{7}{|c|}{ Soil-1 } \\
\hline Control & $33.7 \pm 2.5^{\mathrm{d}}$ & $43.3 \pm 5.0^{\mathrm{ac}}$ & $38.7 \pm 8.6^{\mathrm{d}}$ & $38.7 \pm 7.6^{\mathrm{b}}$ & $41.0 \pm 6.1^{\mathrm{c}}$ & $34.7 \pm 3.2^{\mathrm{b}}$ \\
\hline $\mathrm{KCl}-1$ & $54.7 \pm 2.1^{\mathrm{b}}$ & $55.7 \pm 1.5^{\mathrm{b}}$ & $47.0 \pm 2.0^{\mathrm{ad}}$ & $60.7 \pm 2.5^{\mathrm{a}}$ & $58.7 \pm 3.1^{\mathrm{ab}}$ & $51.3 \pm 4.5^{\mathrm{a}}$ \\
\hline $\mathrm{KCl}-2$ & $46.7 \pm 1.2^{\mathrm{a}}$ & $53.3 \pm 3.2^{\mathrm{ab}}$ & $61.0 \pm 6.0^{\mathrm{bc}}$ & $55.3 \pm 2.5^{\mathrm{a}}$ & $56.7 \pm 4.0^{\mathrm{a}}$ & $49.3 \pm 3.5^{\mathrm{a}}$ \\
\hline $\mathrm{KCl}-3$ & $43.7 \pm 1.5^{\mathrm{a}}$ & $48.0 \pm 6.0^{\mathrm{abc}}$ & $64.3 \pm 3.5^{\mathrm{c}}$ & $54.0 \pm 3.6^{\mathrm{a}}$ & $54.3 \pm 9.1^{\mathrm{ac}}$ & $47.7 \pm 4.0^{\mathrm{ab}}$ \\
\hline $\mathrm{K}_{2} \mathrm{SO}_{4}-1$ & $56.3 \pm 1.5^{\mathrm{b}}$ & $44.0 \pm 5.0^{\mathrm{abc}}$ & $52.0 \pm 3.0^{\mathrm{abc}}$ & $50.7 \pm 4.7^{\mathrm{ab}}$ & $61.0 \pm 2.0^{\mathrm{ab}}$ & $54.0 \pm 2.0^{\mathrm{a}}$ \\
\hline $\mathrm{K}_{2} \mathrm{SO}_{4}-2$ & $52.3 \pm 1.5^{\mathrm{bc}}$ & $37.3 \pm 3.5^{\mathrm{c}}$ & $55.7 \pm 2.3^{\mathrm{abc}}$ & $59.7 \pm 6.5^{\mathrm{a}}$ & $63.7 \pm 2.5^{\mathrm{ab}}$ & $58.3 \pm 5.1^{\mathrm{a}}$ \\
\hline $\mathrm{K}_{2} \mathrm{SO}_{4}-3$ & $48.7 \pm 3.1^{\mathrm{ac}}$ & $49.7 \pm 4.0^{\mathrm{ab}}$ & $49.3 \pm 3.5^{\mathrm{abd}}$ & $61.0 \pm 6.6^{\mathrm{a}}$ & $71.3 \pm 2.5^{\mathrm{b}}$ & $60.7 \pm 8.5^{\mathrm{a}}$ \\
\hline \multicolumn{7}{|c|}{ Soil-2 } \\
\hline Control & $32.0 \pm 2.6^{\mathrm{c}}$ & $36.0 \pm 2.0^{\mathrm{bc}}$ & $22.7 \pm 3.5^{\mathrm{d}}$ & $30.0 \pm 6.6^{\mathrm{a}}$ & $29.7 \pm 9.5^{\mathrm{a}}$ & $27.3 \pm 5.7^{\mathrm{a}}$ \\
\hline $\mathrm{KCl}-1$ & $45.0 \pm 0.0^{\mathrm{a}}$ & $46.0 \pm 2.0^{\mathrm{ab}}$ & $43.7 \pm 5.0^{\mathrm{a}}$ & $44.7 \pm 7.4^{\mathrm{ab}}$ & $44.7 \pm 4.5^{\mathrm{ab}}$ & $44.3 \pm 1.5^{\mathrm{abc}}$ \\
\hline $\mathrm{KCl}-2$ & $45.7 \pm 3.2^{\mathrm{a}}$ & $44.7 \pm 2.3^{\mathrm{ab}}$ & $66.7 \pm 6.7^{\mathrm{c}}$ & $52.3 \pm 4.7^{\mathrm{bc}}$ & $54.7 \pm 6.0^{\mathrm{bc}}$ & $57.7 \pm 6.1^{\mathrm{cd}}$ \\
\hline $\mathrm{KCl}-3$ & $53.3 \pm 3.8^{\mathrm{ab}}$ & $47.3 \pm 1.5^{\mathrm{a}}$ & $63.7 \pm 2.1^{\mathrm{bc}}$ & $64.7 \pm 6.7^{\mathrm{c}}$ & $68.3 \pm 9.5^{\mathrm{c}}$ & $75.7 \pm 7.2^{\mathrm{d}}$ \\
\hline $\mathrm{K}_{2} \mathrm{SO}_{4}-1$ & $52.0 \pm 3.6^{\mathrm{ab}}$ & $32.7 \pm 3.5^{\mathrm{c}}$ & $40.7 \pm 5.7^{\mathrm{a}}$ & $38.3 \pm 5.1^{\mathrm{ab}}$ & $33.7 \pm 0.6^{\mathrm{a}}$ & $36.7 \pm 1.2^{\mathrm{ab}}$ \\
\hline $\mathrm{K}_{2} \mathrm{SO}_{4}-2$ & $56.3 \pm 6.7^{\mathrm{b}}$ & $50.7 \pm 3.1^{\mathrm{ad}}$ & $48.7 \pm 6.5^{\mathrm{ab}}$ & $45.3 \pm 8.1^{\mathrm{ab}}$ & $46.7 \pm 6.4^{\mathrm{ab}}$ & $46.7 \pm 11.0^{\mathrm{abc}}$ \\
\hline $\mathrm{K}_{2} \mathrm{SO}_{4}-3$ & $48.7 \pm 3.1^{\mathrm{ab}}$ & $59.7 \pm 7.6^{\mathrm{d}}$ & $56.7 \pm 10.6^{\mathrm{abc}}$ & $48.3 \pm 7.8^{\mathrm{abc}}$ & $48.3 \pm 6.5^{\mathrm{ab}}$ & $47.7 \pm 9.9^{\mathrm{bc}}$ \\
\hline
\end{tabular}

Explanations as in Table 2.

Changes in the potassium-solubilizing bacteria (KSB) population in the two soils at different fertilizer doses and different incubation periods are presented in Table 8 . The results indicate that the application of both $\mathrm{KCl}$ and $\mathrm{K}_{2} \mathrm{SO}_{4}$ favoured the growth of bacteria with the exception of days 0 and 3 of the incubation period and increased their population relative to that in the untreated soil. The changes in the CFU counts of phosphorus-solubilizing bacteria (PSB) in soils 1 and 2 with different doses of fertilizer application and different incubation periods are presented in Table 9. The initial application of both $\mathrm{KCl}$ and $\mathrm{K}_{2} \mathrm{SO}_{4}$ (i.e. at days 0 and 3$)$ showed no significant $(\mathrm{p}<0.05)$ effect on the PSB population, but during the later incubation days, both fertilizers favoured the growth of the bacteria studied and their populations increased relative to that in the untreated soil. However, no significant $(\mathrm{p}<0.05)$ increase in the PSB population was observed at the end of the incubation as compared to the untreated variant.

For an estimation of the role of individual experimental factors, an analysis of the results was provided by the use of a four-way ANOVA (Table 10). The calculations showed the importance of the rate of fertilizer application more so than the type of fertilizer used, indicating that similar effects could be achieved regardless of the source of the potassium. An analysis of the data showed the substantial effect of the incubation time on all of the measured parameters, where the interactions 
Table 8. Influence of using different potassium fertilizer application rates on the number of potassium-solubilizing bacteria (x $10^{5} \mathrm{CFUs} \mathrm{g}^{-1}$ dry soil) in the tested soils for 60 days of incubation

\begin{tabular}{|c|c|c|c|c|c|c|}
\hline \multirow{2}{*}{ Treatment } & \multicolumn{6}{|c|}{ Incubation days } \\
\hline & 0 & 3 & 7 & 15 & 30 & 60 \\
\hline \multicolumn{7}{|c|}{ Soil-1 } \\
\hline Control & $34.0 \pm 3.0^{\mathrm{a}}$ & $37.3 \pm 7.8^{\mathrm{a}}$ & $30.7 \pm 7.4^{\mathrm{c}}$ & $39.0 \pm 7.0^{\mathrm{b}}$ & $34.0 \pm 4.6^{\mathrm{b}}$ & $33.7 \pm 4.6^{\mathrm{b}}$ \\
\hline $\mathrm{KCl}-1$ & $33.3 \pm 2.1^{\mathrm{a}}$ & $37.0 \pm 2.0^{\mathrm{a}}$ & $45.0 \pm 1.0^{\mathrm{ab}}$ & $49.7 \pm 2.1^{\mathrm{a}}$ & $53.3 \pm 1.5^{\mathrm{a}}$ & $43.7 \pm 1.5^{\mathrm{a}}$ \\
\hline $\mathrm{KCl}-2$ & $36.0 \pm 2.6^{\mathrm{a}}$ & $36.0 \pm 2.0^{\mathrm{a}}$ & $52.0 \pm 3.6^{\mathrm{b}}$ & $52.7 \pm 2.5^{\mathrm{a}}$ & $51.7 \pm 3.5^{\mathrm{a}}$ & $42.0 \pm 3.6^{\mathrm{ab}}$ \\
\hline $\mathrm{KCl}-3$ & $39.3 \pm 2.5^{\mathrm{a}}$ & $35.7 \pm 1.5^{\mathrm{a}}$ & $44.3 \pm 2.5^{\mathrm{ab}}$ & $49.3 \pm 2.5^{\mathrm{ab}}$ & $45.7 \pm 2.5^{\mathrm{a}}$ & $41.3 \pm 2.1^{\mathrm{ab}}$ \\
\hline $\mathrm{K}_{2} \mathrm{SO}_{4}-1$ & $36.3 \pm 2.5^{\mathrm{a}}$ & $41.3 \pm 2.1^{\mathrm{a}}$ & $40.0 \pm 3.6^{\mathrm{ac}}$ & $50.3 \pm 4.2^{\mathrm{a}}$ & $48.0 \pm 2.6^{\mathrm{a}}$ & $49.0 \pm 2.0^{\mathrm{a}}$ \\
\hline $\mathrm{K}_{2} \mathrm{SO}_{4}-2$ & $34.7 \pm 1.2^{\mathrm{a}}$ & $37.3 \pm 2.1^{\mathrm{a}}$ & $37.3 \pm 3.5^{\mathrm{ac}}$ & $53.3 \pm 1.0^{\mathrm{a}}$ & $54.7 \pm 6.0^{\mathrm{a}}$ & $42.3 \pm 5.5^{\mathrm{ab}}$ \\
\hline $\mathrm{K}_{2} \mathrm{SO}_{4}-3$ & $37.0 \pm 1.0^{\mathrm{a}}$ & $33.3 \pm 3.8^{\mathrm{a}}$ & $43.0 \pm 2.6^{\mathrm{ab}}$ & $50.7 \pm 1.5^{\mathrm{a}}$ & $54.3 \pm 1.5^{\mathrm{a}}$ & $44.7 \pm 1.5^{\mathrm{a}}$ \\
\hline \multicolumn{7}{|c|}{ Soil-2 } \\
\hline Control & $35.7 \pm 2.5^{\mathrm{a}}$ & $35.3 \pm 3.2^{\mathrm{a}}$ & $35.0 \pm 1.0^{\mathrm{c}}$ & $37.7 \pm 3.1^{\mathrm{a}}$ & $40.7 \pm 2.9^{\mathrm{d}}$ & $35.7 \pm 2.1^{\mathrm{a}}$ \\
\hline $\mathrm{KCl}-1$ & $34.3 \pm 3.1^{\mathrm{a}}$ & $38.7 \pm 4.7^{\mathrm{a}}$ & $38.0 \pm 3.6^{\mathrm{bc}}$ & $43.3 \pm 2.3^{\mathrm{ab}}$ & $51.0 \pm 2.0^{\mathrm{ab}}$ & $36.7 \pm 2.5^{\mathrm{a}}$ \\
\hline $\mathrm{KCl}-2$ & $36.0 \pm 2.6^{\mathrm{a}}$ & $39.3 \pm 5.5^{\mathrm{a}}$ & $47.0 \pm 2.6^{\mathrm{a}}$ & $41.0 \pm 2.0^{\mathrm{a}}$ & $54.3 \pm 1.5^{\mathrm{a}}$ & $42.7 \pm 4.5^{\mathrm{ab}}$ \\
\hline $\mathrm{KCl}-3$ & $34.3 \pm 2.1^{\mathrm{a}}$ & $38.3 \pm 3.1^{\mathrm{a}}$ & $46.0 \pm 2.6^{\mathrm{a}}$ & $41.7 \pm 2.5^{\mathrm{a}}$ & $58.3 \pm 3.5^{\mathrm{ac}}$ & $41.7 \pm 2.5^{\mathrm{ab}}$ \\
\hline $\mathrm{K}_{2} \mathrm{SO}_{4}-1$ & $33.7 \pm 2.5^{\mathrm{a}}$ & $37.0 \pm 1.7^{\mathrm{a}}$ & $45.3 \pm 2.1^{\mathrm{ab}}$ & $43.0 \pm 2.0^{\mathrm{ab}}$ & $44.0 \pm 3.0^{\mathrm{bd}}$ & $44.3 \pm 2.5^{\mathrm{b}}$ \\
\hline $\mathrm{K}_{2} \mathrm{SO}_{4}-2$ & $38.0 \pm 4.0^{\mathrm{a}}$ & $33.0 \pm 2.0^{\mathrm{a}}$ & $45.3 \pm 3.5^{\mathrm{ab}}$ & $51.0 \pm 5.3^{\mathrm{b}}$ & $51.7 \pm 2.5^{\mathrm{ab}}$ & $48.7 \pm 2.5^{\mathrm{b}}$ \\
\hline$\underline{\mathrm{K}_{2} \mathrm{SO}_{4}-3}$ & $33.0 \pm 5.6^{\mathrm{a}}$ & $35.0 \pm 3.6^{\mathrm{a}}$ & $48.0 \pm 3.0^{\mathrm{a}}$ & $44.7 \pm 2.1^{\mathrm{ab}}$ & $60.7 \pm 4.2^{\mathrm{c}}$ & $56.7 \pm 0.6^{\mathrm{c}}$ \\
\hline
\end{tabular}

Explanations as in Table 2.

Table 9. Influence of using different potassium fertilizer application rates on the number of phosphate-solubilizing bacteria (x $10^{5} \mathrm{CFUs} \mathrm{g}^{-1}$ dry soil) in the tested soils for 60 days of incubation

\begin{tabular}{|c|c|c|c|c|c|c|}
\hline \multirow{2}{*}{ Treatment } & \multicolumn{6}{|c|}{ Incubation days } \\
\hline & 0 & 3 & 7 & 15 & 30 & 60 \\
\hline \multicolumn{7}{|c|}{ Soil-1 } \\
\hline Control & $38.0 \pm 1.7^{\mathrm{a}}$ & $37.7 \pm 6.5^{\mathrm{a}}$ & $30.7 \pm 5.5^{\mathrm{b}}$ & $38.7 \pm 8.1^{\mathrm{a}}$ & $30.0 \pm 4.6^{\mathrm{c}}$ & $38.0 \pm 5.0^{\mathrm{a}}$ \\
\hline $\mathrm{KCl}-1$ & $34.7 \pm 3.5^{\mathrm{a}}$ & $35.3 \pm 3.8^{\mathrm{a}}$ & $48.7 \pm 2.1^{\mathrm{a}}$ & $56.3 \pm 4.5^{\mathrm{b}}$ & $49.0 \pm 7.5^{\mathrm{b}}$ & $39.0 \pm 2.6^{\mathrm{a}}$ \\
\hline $\mathrm{KCl}-2$ & $35.3 \pm 1.2^{\mathrm{a}}$ & $39.0 \pm 2.0^{\mathrm{a}}$ & $45.7 \pm 2.5^{\mathrm{a}}$ & $51.3 \pm 2.5^{\mathrm{ab}}$ & $44.3 \pm 2.5^{\mathrm{ab}}$ & $36.7 \pm 1.2^{\mathrm{a}}$ \\
\hline $\mathrm{KCl}-3$ & $36.0 \pm 3.5^{\mathrm{a}}$ & $41.3 \pm 2.1^{\mathrm{a}}$ & $43.0 \pm 2.6^{\mathrm{a}}$ & $46.7 \pm 2.5^{\mathrm{ab}}$ & $46.7 \pm 3.2^{\mathrm{ab}}$ & $38.7 \pm 2.1^{\mathrm{a}}$ \\
\hline $\mathrm{K}_{2} \mathrm{SO}_{4}-1$ & $38.7 \pm 2.5^{\mathrm{a}}$ & $31.7 \pm 7.6^{\mathrm{a}}$ & $44.3 \pm 1.5^{\mathrm{a}}$ & $51.3 \pm 5.9^{\mathrm{ab}}$ & $46.3 \pm 3.1^{\mathrm{ab}}$ & $34.7 \pm 4.2^{\mathrm{a}}$ \\
\hline $\mathrm{K}_{2} \mathrm{SO}_{4}-2$ & $34.7 \pm 2.1^{\mathrm{a}}$ & $36.3 \pm 1.5^{\mathrm{a}}$ & $45.7 \pm 2.1^{\mathrm{a}}$ & $51.3 \pm 6.7^{\mathrm{ab}}$ & $41.7 \pm 2.5^{\mathrm{ab}}$ & $34.3 \pm 1.5^{\mathrm{a}}$ \\
\hline $\mathrm{K}_{2} \mathrm{SO}_{4}-3$ & $35.7 \pm 4.2^{\mathrm{a}}$ & $31.7 \pm 4.9^{\mathrm{a}}$ & $43.0 \pm 1.7^{\mathrm{a}}$ & $45.3 \pm 3.1^{\mathrm{ab}}$ & $36.7 \pm 2.5^{\mathrm{ac}}$ & $36.0 \pm 3.0^{\mathrm{a}}$ \\
\hline \multicolumn{7}{|c|}{ Soil-2 } \\
\hline Control & $39.3 \pm 2.5^{\mathrm{bc}}$ & $41.7 \pm 2.5^{\mathrm{a}}$ & $38.7 \pm 2.1^{\mathrm{b}}$ & $41.7 \pm 3.2^{\mathrm{a}}$ & $40.0 \pm 5.3^{\mathrm{a}}$ & $37.0 \pm 1.0^{\mathrm{a}}$ \\
\hline $\mathrm{KCl}-1$ & $39.0 \pm 2.0^{\mathrm{b}}$ & $45.3 \pm 3.1^{\mathrm{a}}$ & $41.0 \pm 2.0^{\mathrm{b}}$ & $54.7 \pm 2.5^{\mathrm{b}}$ & $58.3 \pm 2.5^{\mathrm{b}}$ & $36.7 \pm 5.1^{\mathrm{a}}$ \\
\hline $\mathrm{KCl}-2$ & $42.3 \pm 1.5^{\mathrm{abc}}$ & $51.3 \pm 2.1^{\mathrm{a}}$ & $52.3 \pm 1.5^{\mathrm{a}}$ & $52.0 \pm 5.3^{\mathrm{ab}}$ & $55.3 \pm 8.1^{\mathrm{ab}}$ & $33.7 \pm 7.5^{\mathrm{a}}$ \\
\hline $\mathrm{KCl}-3$ & $45.3 \pm 3.1^{\mathrm{a}}$ & $46.0 \pm 2.0^{\mathrm{a}}$ & $47.7 \pm 3.5^{\mathrm{a}}$ & $50.3 \pm 5.7^{\mathrm{ab}}$ & $48.0 \pm 10.1^{\mathrm{ab}}$ & $35.0 \pm 3.0^{\mathrm{a}}$ \\
\hline $\mathrm{K}_{2} \mathrm{SO}_{4}-1$ & $44.7 \pm 1.5^{\mathrm{abc}}$ & $45.0 \pm 5.3^{\mathrm{a}}$ & $47.7 \pm 2.1^{\mathrm{a}}$ & $53.3 \pm 2.5^{\mathrm{ab}}$ & $49.0 \pm 3.6^{\mathrm{ab}}$ & $37.3 \pm 1.5^{\mathrm{a}}$ \\
\hline $\mathrm{K}_{2} \mathrm{SO}_{4}-2$ & $48.0 \pm 1.0^{\mathrm{a}}$ & $46.0 \pm 2.6^{\mathrm{a}}$ & $48.7 \pm 2.5^{\mathrm{a}}$ & $53.3 \pm 4.0^{\mathrm{ab}}$ & $45.3 \pm 4.7^{\mathrm{ab}}$ & $41.3 \pm 2.9^{\mathrm{a}}$ \\
\hline $\mathrm{K}_{2} \mathrm{SO}_{4}-3$ & $45.0 \pm 2.6^{\mathrm{a}}$ & $41.0 \pm 6.6^{\mathrm{a}}$ & $40.7 \pm 2.5^{\mathrm{b}}$ & $52.7 \pm 5.1^{\mathrm{ab}}$ & $40.0 \pm 3.6^{\mathrm{a}}$ & $36.7 \pm 1.5^{\mathrm{a}}$ \\
\hline
\end{tabular}

Explanations as in Table 2.

were strengthened by the rate of fertilizer application. Among the measured variables, the $\mathrm{EC}_{\mathrm{e}}$ levels seemed to be the most substantially affected parameter, because it was primarily altered by the application rates of the different fertilizers.

\section{DISCUSSION}

In general, the application of potassium fertilizers helps to increase soil acidity as the fertilizer dose is increased but this effect is neutralized with the progress of time. The findings of Du et al. (2010) also indicated that the decrease in soil $\mathrm{pH}$ induced by $\mathrm{KCl}$ application was significantly influenced to a significant extent by the incubation time and that the developing acidity of the soil was neutralized with the progress of time. The study indicated that the application of fertilizer increased the $\mathrm{EC}_{\mathrm{e}}$ values with increasing doses as compared to the control. The lower $\mathrm{EC}_{\mathrm{e}}$ values in the case of $\mathrm{K}_{2} \mathrm{SO}_{4}$ application as compared to $\mathrm{KCl}$ (although not always clearly verified by a statistical evaluation of the data) indicated the slow dissociation of the $\mathrm{K}_{2} \mathrm{SO}_{4}$ salt, as stated by Zehler (1981).

Changes in basal soil respiration are related to the increasing populations of the microbial community which increased with increased fertilizer dose, this was also observed by Zakarauskaite et al. (2008). In this experiment, the population of the different bacterial communities tended to increase because of the application of potassium fertilizers, but the unaltered or more or less stable respiration values 


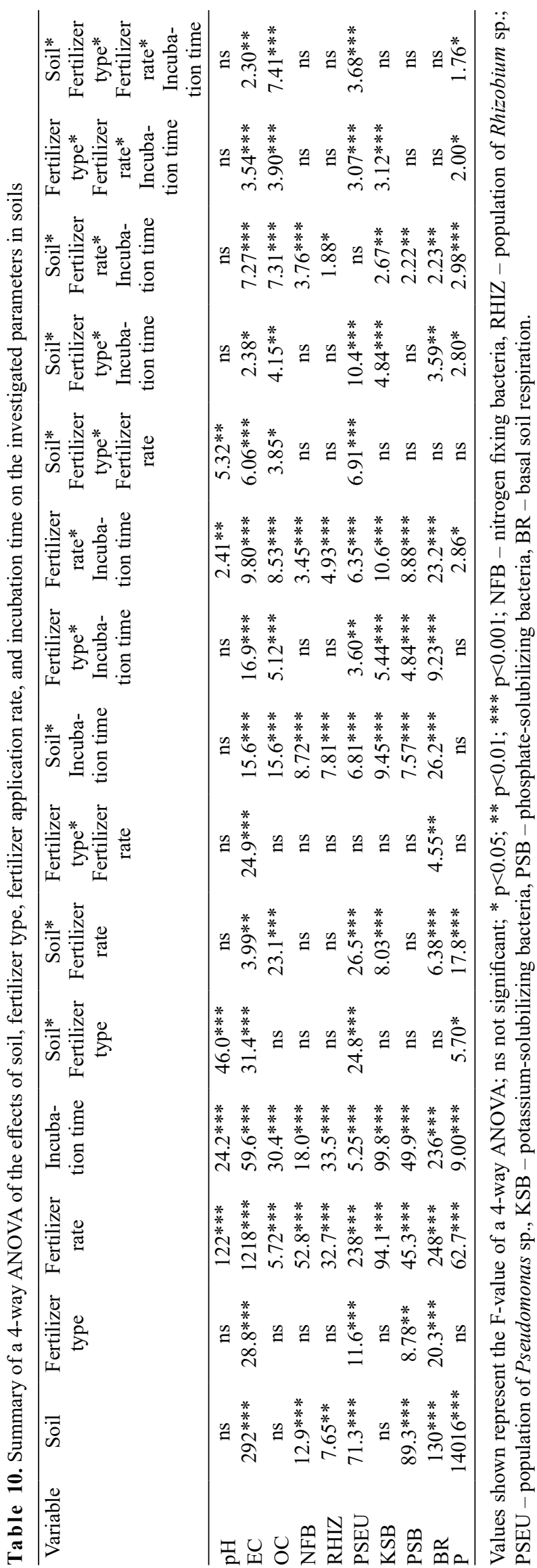

at different doses of fertilizer $\left(40,110\right.$, and $\left.180 \mathrm{~kg} \mathrm{ha}^{-1}\right)$ indicated that the community always maintains an equilibrium in their metabolic level. This may be the result of the increasing population of the community with increasing dosage which may be attributed to the fact that the addition of fertilizers to soil generally stimulates the microbial ecosystem. Moreover, as reported by Geisseler and Scow (2014), metabolic activity does not only respond to mineral fertilization, but it also represents the results of many other factors, such as physiological stress, physical disturbances, a shift in the composition of the microbial community etc. In this study, the results indicated that the higher doses of potassium fertilizers chosen for the study, which are commonly used doses for various crops, did not ultimately exert any adverse effect on the beneficial microbial population of the soil.

With regard to changes in $\mathrm{CO}_{2}$ evolution by microorganisms during the incubation period, a significant increase in $\mathrm{CO}_{2}$ evolution was observed for all of the potassium treated variants as compared to the control with the exception of sampling days 0 and 3 . The increase in the rate of microbial respiration on successive incubation days may occur because of the lower availability of easily decomposable organic matter during the initial period of the study which later became available because of the degrading population of microorganisms, the oxidation of which liberated larger amounts of $\mathrm{CO}_{2}$ through microbial respiration (Wu and Ma, 2001). A reduction in the evolution of $\mathrm{CO}_{2}$ by microorganisms during the later phases of incubation as a consequence of the lower availability of organic carbon, as a result of its exhaustion over time (Usman et al., 2004, 2013) was not observed in this study.

In general, fertilizer stimulates microbial growth and may affect the composition of individual microbial communities (Khonje et al., 1989). Naher et al. (2013) reported that the total bacterial, fungal, and actinomycetes population increased significantly as a result of fertilizer treatment in comparison to the control. It was found that the application of both potassium fertilizers at lower doses stimulated nitrogen-fixing bacteria and Rhizobium sp. populations in both soils to a significant extent in most variants of the experiment. The trend towards a decrease in this type of bacterial population among several variants with the application of high doses of $\mathrm{KCl}$ may be attributed to an increase in the acidity of the treated soil which may impart stress and result in a decrease in the bacterial population. Moreover, the results confirmed that the application of fertilizers did not impose any severe persistent negative influence on the population of either free-living nitrogen fixers or Rhizobium sp.

Considering the overall effect on the Pseudomonas population, the results indicated an increase in their population in the treated soils as compared to the untreated control. These results are well corroborated by the findings of Deshwal and Kumar (2013) in which an increasing trend in the Pseudomonas population with increasing salt 
concentration in the soil was reported; this observation may be a result of the excretion by Pseudomonas sp. of exo-polysaccharides that bind with salt ions $\left(\mathrm{Na}^{+}, \mathrm{K}^{+}\right.$, etc. $)$in the soil solution resulting in a decrease in salinity stress (Ashraf et al., 2004; Kohler et al., 2006; Nadeem et al., 2010) and thereby increasing the population of Pseudomonas sp. at higher doses of the fertilizer as compared to the control.

The results of the activity of potassium-solubilizing bacteria are in agreement with the findings of Parmar and Sindhu (2013) which showed that the application of potassium fertilizers $\left(\mathrm{KCl}\right.$ and $\left.\mathrm{K}_{2} \mathrm{SO}_{4}\right)$ positively influences the activity of potassium-solubilizing bacteria. In general, a higher KSB population was registered with lower doses of $\mathrm{KCl}$ and $\mathrm{K}_{2} \mathrm{SO}_{4}$ in Soil-1, whereas the reverse of this trend was observed in Soil-2 but without a clear statistical verification of all of the findings. Moreover, the higher doses of application of both fertilizers did not exert any serious negative influence on the population of the potassium-solubilizing bacterial community. The increasing soil acidity due to potassium fertilization was also supported by the increasing population of potassium-solubilizing bacteria which produced larger amount of organic acids for the solubilization of $\mathrm{K}$ from exchange complexes in the soil. It has been established that an increase in the potassium-solubilizing bacterial population significantly increases the amount of different organic acids viz. oxalic acid, tartaric acids, gluconic acid, 2-ketogluconic acid, citric acid, malic acid, succinic acid, lactic acid, propionic acid, glycolic acid, malonic acid and fumaric acid in the soil microsystem (Hu et al., 2006; Keshavarz Zarjani et al., 2013; Krishnamurthy, 1989; Liu et al., 2012; Prajapati et al., 2012, 2013; Saiyad et al., 2015; Sheng and He, 2006). However, Moro et al. (2014) assumed that $\mathrm{K}$ is not among the limiting nutrients for soil microorganisms. As stated by Etesami et al. (2017), the interactions of KSB with other soil beneficial organisms should also be included in the experimental designs of future research.

The results concerning the activity of phosphate-solubilizing bacteria were very similar to the findings of New et al. (2013) in which the phosphate-solubilizing activity by the bacterial population was affected by higher levels of salt concentration; the effects differ according to the different species of microorganisms involved (Chookietwattana, 2003). Microorganisms under stress conditions either die or remain dormant, the exceptions are halotolerant and halophilic microorganisms which have the ability to combat this problem. On the other hand, P-solubilizing microorganisms can help to reduce the harmful effects of excess nutrients in the soil (Altomare and Tringovska, 2011). In this experiment, the maximum values of CFUs occurred at day 15 of the incubation and the importance of the incubation time was verified with the application of multivariate statistics. This trend may be a result of the depletion of nutrients in the soil during the second part of the incubation. Moreover, the balanced combined use of P-solubilizing microorganisms with mineral fertilizers may lead to an effective enhancement of the mobilization of $\mathrm{P}$ resources in soils (Altomare and Tringovska, 2011).

\section{CONCLUSIONS}

1. A multivariate analysis of the data indicated the predominant importance of the incubation time and fertilizer application rate on the studied parameters whereas the fertilizer type seems to have less of an effect on these parameters.

2. An increase in the population of some agriculturally beneficial soil microorganisms was observed with the application of potassium fertilizers. Moreover, the application of potassium fertilizers positively influenced basal soil respiration in comparison to that of the control.

3. In summary, for the potential improvement of soil biological parameters, the $\mathrm{K}$ fertilizer dose considerably influenced the soil microbial population structures, but the type of applied K fertilizer seems to be less important. Thus, for a balanced K supply, Indian farmers should choose the $\mathrm{K}$ fertilizer type according to its availability and price.

Conflict of interest: The authors declare that they have no conflict of interest.

\section{ACKNOWLEDGMENTS}

We are grateful to Swami Atmapriyanandaji Maharaj, Hon'ble Vice Chancellor of Ramakrishna Mission Vivekananda University (RKMVU) for his valuable encouragement. We also thank Dr. Indranil Das, Assistant Director of Agriculture, Fertilizer Control Laboratory, Govt. of West Bengal, Berhampore, Murshidabad for his contribution in the statistical calculations. Dr. Kathryn Wright, freelance editor and proofreader, UK, provided improvement of language.

\section{REFERENCES}

Alef K., 1991. Methodenhandbuch bodenmikrobiologie: aktivitäen, biomasse, differenzierung. [place unknown]: Ecomed-Verlag-Ges

Altomare C. and Tringovska I., 2011. Beneficial soil microorganisms, an ecological alternative for soil fertility management. In: Genetics, Biofuels and Local Farming Systems (Ed. E. Lichtfouse). Sustain. Agric. Rev., vol. 7. Springer, Dordrecht, https://doi.org/10.1007/978-94-007-1521-9

Anderson T.H., 2003. Microbial eco-physiological indicators to asses soil quality. Agric. Ecosyst. Environ., 98, 285-293, https://doi.org/10.1016/S0167-8809(03)00088-4

Ashraf M., Hasnain S., Berge O., and Mahmood T., 2004. Inoculating wheat seedlings with exopolysaccharide - producing bacteria restricts sodium uptake and stimulates plant growth under salt stress. Biol. Fertil. Soils, 40, 157162, https://doi.org/10.1007/s00374-004-0766-y

Bray R.H. and Kurtz L.T., 1945. Determination of total, organic, and available forms of phosphorus in soils. Soil Sci., 59, 3946, https://doi.org/10.1097/00010694-194501000-00006 
Chookietwattana K., 2003. Diversity of halophilic bacteria in saline soil at Nongbo reservoir, Mahasarakham province, Thailand. PhD thesis, Suranaree University of Technology.

Das D., Dwivedi B.S., Datta S.P., Datta S.C., Meena M.C., Agarwal B.K., Shahi D.K., Singh M., Chakraborty D., and Jaggi S., 2019. Potassium supplying capacity of a red soil from Eastern India after forty-two years of continuous cropping and fertilization. Geoderma, 341, 76-92, https:// doi.org/10.1016/j.geoderma.2019.01.041

Deshwal V.K. and Kumar P., 2013. Effect of salinity on growth and PGPR activity of Pseudomonads. J. Acad. Ind. Res., 2, 353-356.

Dhiman D., Sharma R., Sankhyan N.K., Sepehya S., Sharma S.K., and Kumar R., 2019. Effect of regular application of fertilizers, manure and lime on soil health and productivity of wheat in an acid Alfisol. J. Plant Nutr., 42, 2507-2521, https://doi.org/10.1080/01904167.2019.1659317

Du Z., Zhou J., Wang H., Chen X., and Wang Q., 2010. Soil pH changes from fertilizer site as affected by application of monocalcium phosphate and potassium chloride. Commun. Soil Sci. Plant Anal., 41, 1779-1788, https://doi.org/10.108 0/00103624.2010.492064

Etesami H., Emami S., and Alikhani H.A., 2017. Potassium solubilizing bacteria (KSB): Mechanisms, promotion of plant growth, and future prospects - a review. J. Soil Sci. Plant Nutr., 17, 897-911, http://dx.doi.org/10.4067/ S0718-95162017000400005

Geisseler D. and Scow K.M., 2014. Long-term effects of mineral fertilizers on soil microorganisms - a review. Soil Biol. Biochem., 75, 54-63, https://doi.org/10.1016/j.soilbio.2014.03.023

Ghiri M.N. and Abtahi A., 2011. Potassium dynamics in calcareous vertisols of southern Iran. Arid Land Res. Manag,. 25, 257-274, https://doi.org/10.1080/15324982.2011.565857

Gurav P.P., Datta S.C., Ray S.K., Choudhari P.L., and Ahmed N., 2018. Assessment of potassium release threshold levels of Vertisols (shrink-swell soils) in different agro-ecological regions of India. Appl. Clay Sci., 165, 155-163, https://doi. org/10.1016/j.clay.2018.08.008

Gurav P.P., Ray S.K., Choudhari P.L., Shirale A.O., Meena B.P., Biswas A.K., and Patra A.K., 2019. Potassium in shrink-swell soils of India. Current Sci., 117, 587-596, https://doi.org/10.18520/cs/v117/i4/587-596

Hu X., Chen J., and Guo J., 2006. Two phosphate-and potassium-solubilizing bacteria isolated from Tianmu Mountain, Zhejiang, China. World J. Microbiol. Biotechnol., 22, 983990, https://doi.org/10.1007/s11274-006-9144-2

Kaschuk G., Alberton O., and Hungria M., 2010. Three decades of soil microbial biomass studies in Brazilian ecosystems: Lessons learned about soil quality and indications for improving sustainability. Soil Biol. Biochem., 42, 1-13, https://doi.org/10.1016/j.soilbio.2009.08.020

Kayasth M., Gera R., Dudeja S.S., Sharma P.K., and Kumar V., 2014. Studies on salinization in Haryana soils on free-living nitrogen-fixing bacterial populations and their activity. J. Basic Microbiol., 54, 170-179, https://doi. org/10.1002/jobm.201200158

Keshavarz Zarjani J., Aliasgharzad N., Oustan S., Emadi M., and Ahmadi A., 2013. Isolation and characterization of potassium solubilizing bacteria in some Iranian soils. Arch. Agron. Soil Sci., 59, 1713-1723, https://doi.org/10.1080/03 650340.2012 .756977
Khonje D., Varsa E., and Klubek B., 1989. The acidulation effects of nitrogenous fertilizers on selected chemical and microbiological properties of soil. Commun. Soil Sci. Plant Anal., 20, 1377-1395, https://doi.org/10.1080/00103628909368156

Kohler J., Caravaca F., Carrasco L., and Roldan A., 2006. Contribution of Pseudomonas mendocina and Glomus intraradices to aggregate stabilization and promotion of biological fertility in rhizosphere soil of lettuce plants under field conditions. Soil Use Manag., 22, 298-304, https://doi. org/10.1111/j.1475-2743.2006.00041.x

Krishnamurthy H.A., 1989. Effect of pesticides on phosphate solubilizing microorganisms. M. Sc. (Agric.) thesis, University of Agricultural Sciences, Dharwad.

Lindeman R.H., Merenda P.F., and Gold R.Z., 1980. Introduction to Bivariate and Multivariate Analysis. Glenview, Illinois (Scott, Foresman).

Liu D., Lian B., and Dong H., 2012. Isolation of Paenibacillus sp. and assessment of its potential for enhancing mineral weathering. Geomicrobiol. J., 29, 413-421, https://doi.org/10.1080 /01490451.2011.576602

Mbuthia L.W., Acosta-Martínez V., DeBruyn J., Schaeffer S., Tyler D., Odoi E., Mpheshea M., Walker F., and Eash N., 2015. Long term tillage, cover crop, and fertilization effects on microbial community structure, activity: Implications for soil quality. Soil Biol. Biochem., 89, 24-34, https:// doi.org/10.1016/j.soilbio.2015.06.016

Meena V.S., Bahadur I., Maurya B.R., Kumar A., Meena R.K., Meena S.K., and Verma J.P., 2016. Potassium-Solubilizing Microorganism in Evergreen Agriculture: An Overview. In: Potassium Solubilizing Microorganisms for Sustainable Agriculture (Eds V. Meena, B. Maurya, J. Verma, R. Meena). Springer, New Delhi, https://doi. org/10.1007/978-81-322-2776-2

Moro H., Kunito T., Saito T., Yaguchi N., and Sato T., 2014. Soil microorganisms are less susceptible than crop plants to potassium deficiency. Arch. Agron. Soil Sci., 60, 18071813, https://doi.org/10.1080/03650340.2014.918960

Nadeem S.M., Zahir Z.A., Naveed M., Asghar H.N., and Arshad M., 2010. Rhizobacteria capable of producing ACC-deaminase may mitigate salt stress in wheat. Soil Sci. Soc. Am. J., 74, 533542, https://doi.org/10.2136/sssaj2008.0240

Naher U.A., Othman R., and Panhwar Q.A., 2013. Culturable total and beneficial microbial occurrences in long-term nutrient deficit wetland rice soil. Aust. J. Crop Sci., 7, 1848

New M.T., Yu S., and Latt Z., 2013. Study on phosphate solubilization of salt tolerant soil yeast isolates and effects on maize germination and growth. Int. J. Adv. Appl. Sci., 2, 157-164, https://doi.org/10.11591/ijaas.v2i3.5903

Parkinson D. and Coleman D.C., 1991. Microbial communities, activity and biomass. Agric. Ecosyst. Environ., 34, 3-33, https://doi.org/10.1016/0167-8809(91)90090-K

Parmar P. and Sindhu S.S., 2013. Potassium solubilization by rhizosphere bacteria: Influence of nutritional and environmental conditions. J. Microbiol. Res., 3, 25-31, https://doi. org/10.5923/j.microbiology.20130301.04

Pathak H., Mohanty S., Jain N., and Bhatia A., 2010. Nitrogen, phosphorus, and potassium budgets in Indian agriculture. Nutr. Cycl. Agroecosyst., 86, 287-299, https://doi. org/10.1007/s10705-009-9292-5 
Pikovskaya R.I., 1948. Mobilization of phosphorus in soil in connection with the vital activity of some microbial species [Internet]. [accessed 2020 Feb 11]. https://www.scienceopen.com/ document?vid=44a8aa7f-fad0-4038-a97b-a766d1a3b6fb

Prajapati K., Sharma M., and Modi H., 2012. Isolation of two potassium solubilizing fungi from ceramic industry soils. Life Sci. Leaflets, 5, 71-75.

Prajapati K., Sharma M.C., and Modi H.A., 2013. Growth promoting effect of potassium solubilizing microorganisms on okra (Abelmoschus esculentus). Int. J. Agric. Sci. Res., 1, 181-188.

Rasmussen P.E., Goulding K.W.T., Brown J.R., Grace P.R., Janzen H.H., and Körschens M., 1998. Long-term agroecosystem experiments: Assessing agricultural sustainability and global change. Science, 282, 893-896, https://doi. org/10.1126/science. 282.5390 .893

Rawat J., Sanwal P., and Saxena J., 2016. Potassium and its role in sustainable agriculture. In: Potassium Solubilizing Microorganisms for Sustainable Agriculture (Eds V.S. Meena, B.R. Maurya, J.P. Verma, R.S. Meena). [Internet]. New Delhi: Springer India; [accessed 2020 Feb 11]; pp. 235-253, https://doi.org/10.1007/978-81-322-2776-2_17

Saiyad S.A., Jhala Y.K., and Vyas R.V., 2015. Comparative efficiency of five potash and phosphate solubilizing bacteria and their key enzymes useful for enhancing and improvement of soil fertility. Int. J. Sci. Res. Publ., 5, 1-6.

Sarathchandra S.U., Perrott K.W., Boase M.R., and Waller J.E., 1988. Seasonal changes and the effects of fertiliser on some chemical, biochemical and microbiological characteristics of high-producing pastoral soil. Biol. Fertil. Soils, 6, 328-335, https://doi.org/10.1007/BF00261022

Scherer H.W., 2005. Fertilizers and fertilization. In: Encyclopedia of Soils in the Environment (Ed. D. Hillel), Elsevier, pp. 20-26, https://doi.org/10.1016/B0-12-348530-4/00229-0

Sheng X.F. and He L.Y., 2006. Solubilization of potassium-bearing minerals by a wild-type strain of Bacillus edaphicus and its mutants and increased potassium uptake by wheat. Can. J. Microbiol., 52, 66-72, https://doi.org/10.1139/w05-117
Usman A.R., Alkredaa R.S., and Al-Wabel M., 2013. Heavy metal contamination in sediments and mangroves from the coast of Red Sea: Avicennia marina as potential metal bioaccumulator. Ecotoxicol. Environ. Safe., 97, 263-270, https:// doi_org/10.1016/j.ecoenv.2013.08.009

Usman A.R., Kuzyakov Y., and Stahr K., 2004. Effect of clay minerals on immobilization of heavy metals and microbial activity in a sewage sludge-contaminated soil. Chem. Ecol., 20, 123135, https://doi.org/10.1080/02757540410001665971

Verma P., Yadav A.N., Khannam K.S., Saxena A.K., and Suman A., 2017. Potassium-Solubilizing Microbes: Diversity, Distribution, and Role in Plant GrowthPromotion. In: Microorganisms for Green Revolution. Microorganisms for Sustainability (Eds D. Panpatte, Y. Jhala, R. Vyas, H. Shelat). vol. 6. Springer, Singapore, https://doi.org/10.1007/978-981-10-6241-4_7

Wu L. and Ma L., 2001. Effects of sample storage on biosolids compost stability and maturity evaluation. J. Environ. Qual., 30, 222-228, https://doi.org/10.2134/jeq2001.301222x

Yadav B.K. and Sidhu A.S., 2016. Dynamics of potassium and their bioavailability for plant nutrition. In: Potassium Solubilizing Microorganisms for Sustainable Agriculture (Eds V. Meena, B. Maurya, J. Verma, R. Meena). Springer, New Delhi, https://doi.org/10.1007/978-81-322-2776-2_14

Zakarauskaitė D., Vaišvila Z., Motuzas A., Grigaliūnienè K., Buivydaitè V.V., Vaisvalavičius R., and Butkus V., 2008. The influence of long-term application of mineral fertilizers on the biological activity of Cambisols. Ekologija, 54, 173-178, https://doi.org/10.2478/v10055-008-0027-8

Zehler E., Kreipe H., and Gething P., 1981. Potassium sulphate and potassium chloride - Their influence on the yield and quality of cultivated plants. International Potash Institute, Worblaufen-Bern, Switzerland.

Zörb C., Senbayram M., and Peiter E., 2014. Potassium in agriculture-status and perspectives. J. Plant Physiol., 171, 656-669, https://doi.org/10.1016/j.jplph.2013.08.008 